\title{
Bioenergy sustainable development: achieving the balance between social and economic aspects
}

\author{
Vitalii Kovalenko, ${ }^{1,}$, Nataliya Kovalenko ${ }^{2}$, Oleksandr Labenko $^{3}$, Oleksandr Faichuk ${ }^{4}$, Olha \\ Faichuk $^{5}$ \\ ${ }^{1} \mathrm{PhD}$ in Agricultural Sciences, Associate Professor, Department of fodder production, reclamation \\ and meteorology, 03041 National University of Life and Environmental Sciences of Ukraine, Kyiv, \\ Ukraine \\ ${ }^{2} \mathrm{PhD}$ in Economics, Associate Professor, Department of administrative management and foreign \\ economic activity, 03041 National University of Life and Environmental Sciences of Ukraine, Kyiv, \\ Ukraine \\ ${ }^{3} \mathrm{PhD}$ in Economics, Associate Professor, Department of Finance, 03041 National University of Life \\ and Environmental Sciences of Ukraine, Kyiv, Ukraine \\ ${ }^{4} \mathrm{PhD}$ in Economics, Associate Professor, Department of administrative management and foreign \\ economic activity, 03041 National University of Life and Environmental Sciences of Ukraine, Kyiv, \\ Ukraine \\ ${ }^{5} \mathrm{PhD}$ in Economics, Associate Professor, Department of banking and insurance, 03041 National \\ University of Life and Environmental Sciences of Ukraine, Kyiv, Ukraine
}

\begin{abstract}
At the beginning of the third Millennium, humanity is forced to face a new surge of tensions and contradictions between different countries and peoples, between different parties and faiths, as well as the growth of environmental, economic and social problems both in different regions of the world and on a global scale. These phenomena are the result of the exhaustion of socio-economic forms of development of society within the existing natural resource and environmental conditions. An increasing number of people and states are experiencing an acute shortage not only in quality food, but also in quality water, clean air, energy, land, biological and other resources. After all, according to some scientists over the past hundred years, the consumption of natural resources by mankind has increased almost 100 times. For the first time in the history of mankind, resource and environmental crises have reached the biosphere borders and there is a danger to the existence of civilization. Humanity faces a global challenge, the correct solution of which will result on the lives of our descendants in the future. The common task for all is to preserve the biosphere as the habitat of mankind. Further increase of material and energy flows becomes impossible, as well as further satisfaction of the needs of new billions of people who will be added to the total population. Humanity is on the threshold of a new socio-economic formation, as neither a centrally managed economy nor a market economy has been able to solve the global environmental problems of our planet.
\end{abstract}

\footnotetext{
* Corresponding author: vpkovalenko04@gmail.com
} 


\section{Introduction}

Humanity is investing a lot of money, is looking for new ways to get energy. It needs to solve the basic needs necessary for a safe and comfortable life. Safe - because today because of oil and gas there are conflicts and wars, changing governments, some countries become richer other poorer, of great importance is its impact on the environment. Comfortable - because the level of material and spiritual culture depends on the amount of energy possessed by a particular state. The needs of mankind, as well as the number of the population, are growing every year.

Energy use is an important factor in living standards. In those days, when a person extracted food, collecting forest fruits, and engaged in hunting, the need for energy for a day was $8 \mathrm{MJ}$, with primitive agricultural production - 50 MJ, and in a more developed society $-100 \mathrm{MJ}$.

The need of mankind for energy resources is growing at a faster rate than the number of people on Earth. The demand for traditional energy sources has increased more than 31 times over the past 100 years, due to the growth of the world population and the growth of energy consumption by the population, respectively, 3.8 and 8.5 times.

The national economy today mainly uses non-renewable sources of energy raw materials (oil, gas, coal). With constant consumption, they will be exhausted in the future. Energy security, like food security, is an important and topical issue for any country in the world. The satisfactory level of energy security of the country is proved by the full satisfaction of its needs for energy resources, in turn, the appropriate level of food security of the country is proved by the level of food security of the population, which guarantees socio-political stability in society, the survival and development of the nation, the individual, the family, sustainable economic development.

\section{Results and Discussion}

Energy security involves achieving a state of technically reliable, stable, cost-effective and environmentally safe provision of energy resources to the economy and social sphere of the state.

Energy security of Ukraine should be understood as the ability of the state to ensure the effective use of its own fuel and energy base, to carry out the optimal diversification of sources and ways of supplying energy to Ukraine to ensure the life of the population and the functioning of the national economy in the normal, emergency and martial law, to prevent sharp price fluctuations in fuel and energy resources, or to create conditions for the painless adaptation of the national economy to the new prices for these resources [1].

As defined in the energy policy review of Ukraine by the International Energy Agency (IEA), the most significant threats to Ukraine's energy security at the present stage should be considered:

- low energy efficiency (energy efficiency is defined as a priority for strengthening energy security, which is very important for its economic progress and environmental protection);

- lack of mechanisms to neutralize high energy prices;

- low investment attractiveness of the country's energy sector (in order to attract investment and create incentives for the continuation of market reforms in many areas of the fuel and energy sector it is necessary that prices reflect the real cost of energy resources);

- lack of transparency in the energy sector and unclear definition of market rules [2].

The need to ensure food security of the country requires maintaining an appropriate level of food self-sufficiency, which involves the use of state support for domestic 
agricultural producers and the adoption of import control measures to protect their own producers from foreign competition. Reliability of food security lies both in sufficient selfsufficiency in food and in the availability of the means to import it in the required quantities, with the minimum potential vulnerability of the food supply of the population in the event of difficulties in importing food (lack of currency, rising prices, embargoes and the like) [3].

Developed countries like the USA, Japan and Europe pay constant attention to the problems of food stability and security. The changes taking place in the world are associated with climatic cataclysms, economic and political changes, with the development of bioenergy directions are related and intersect with the definition of food security. The agri-food policy of the states ensures the effective development of the agro-industrial complex, which in turn is the basis for the food supply of the population.

Recently, all countries of the world are concerned about both their own food security and the world food security as a whole. Experts explain the global rise in food prices by three factors. First, the growth of consumption and, accordingly, the demand for food, as well as changes in the structure of consumption of the population of India and China. Secondly, the increase in biofuel production, that is, the use of land not for food production. And thirdly, the climatic changes caused by crop failures, as well as the overall reduction of acreage. In the last 20 years alone, more than $50 \%$ of arable land has become modern urban settlements [4].

Leading experts of the world conduct researches, which analyze and predict the development of mankind: the increase in the world's population, changes in the needs of the population in terms of providing food for that energy consumption. According to the latest forecasts in the next 50 years, the world's population will increase by three billion and reach nine billion people.

The projected dynamics of world population growth by continent for the period 19502050 is shown graphically in Fig. 1.

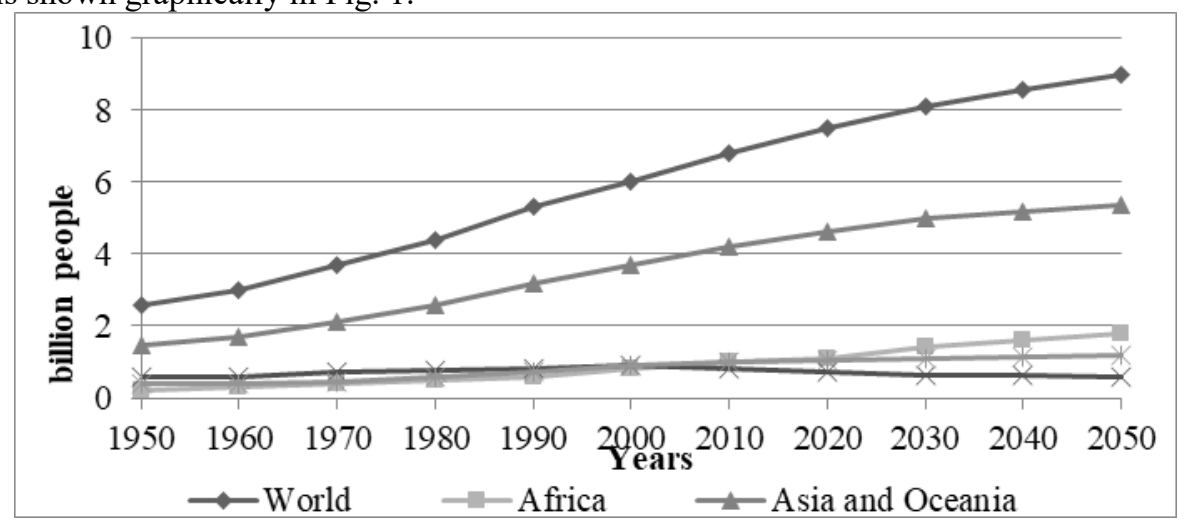

Fig. 1. Dynamics of world population growth by continent.

Source: author's research according to FAO

As can be seen from the graph, in the next 40 years, the largest population growth is expected in Asia and Oceania (an increase from almost 4 billion people to 5.2 billion people in 2050), Africa (from 1 billion people to 1.8 billion people). In Europe, on the contrary, we expect a decrease in the population, America will develop relatively stable.

The increase in the number of people in the world will lead to an increase in the needs of mankind in food. The main task of mankind in solving food problems is to provide the population of each country and the world as a whole with sufficient food. This can be done only through the formation of a stable developed agriculture, which is able to increase its production volumes more rapidly than the growth of the world population. This will make 
it possible to eliminate the shortage of products in those regions of the world where it is observed. According to the Food and Agriculture Organization (FAO), the need for food will grow to more than 90,000 billion kcal worldwide. per year. The population of industrialized countries is about $30 \%$ of the total world population, these countries account for $60 \%$ of world production. About $2 / 3$ of the world's population live in developing countries, but the rate of increase in food production is far behind the rate of increase in demand. Average food consumption per person in developed countries is 3,390 calories, while in developing countries it is only 2,070 calories per day. Mass starvation can be a threat for two main reasons: the temporary disruption of "normal" climatic conditions in any region or country, or the emergence of permanent "chronic hunger", which is the result of the underdeveloped state of the country's economy. The dynamics of the growth of food demand in the world is shown in Fig. 2.

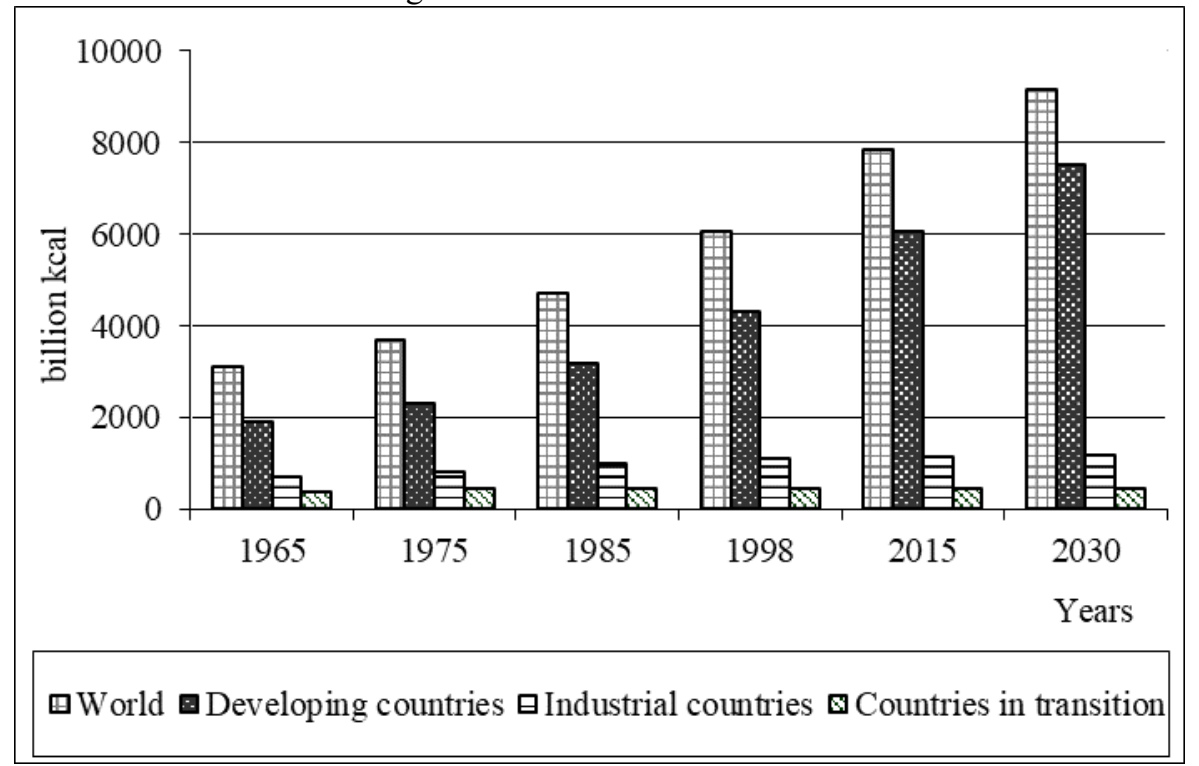

Fig. 2. Increasing demand for food supply for the world's population.

Source: author's research according to FAO

As evidenced by the data shown in Fig. 2, the greatest need for food will increase in developing countries. This is a reaction to the increase in the population of these countries, as well as improving their living standards, which in turn leads to improved food balances, compliance with human nutrition standards. Most of all, according to the research of the Food and Agriculture Organization (FAO), meat consumption will increase, which will require additional investment in the livestock sector and expansion of areas for forage.

When incomes begin to grow in traditionally poor countries, people first try to diversify their diet by consuming large quantities of meat products.

The world level of meat production has almost doubled since 1950, keeping pace with the increase in the population. In the growth of meat production, the first stood out industrially developed countries of the West and Japan. However, over the past few decades, the same trends have developed in the countries of East Asia, the Middle East and Latin America. Beef, pork, poultry are the basis of world meat consumption.

On Earth, there is a dynamic growth of the population and, accordingly, it should cause a dynamic growth in the volume of industry and agriculture, which are aimed at meeting the constantly increasing needs of the population. However, the area of territories suitable for human activity on Earth is limited. 
The amount of natural raw materials (those that need hundreds of millions of years to renew) is also limited. And industry and energy are the basis of the life of modern civilization.

The raw material crisis is already relevant for the industrialized countries of the West their mineral reserves are small, and almost exhausted.

The increase in population is accompanied by a growing shortage of agricultural land. If we take into account the use of land for urban and industrial construction, the amount of land that remains for agricultural production is reduced compared to the total reserves of agricultural land. Accordingly, the number of agricultural lands per person decreases (table $1)$.

Table 1. World agricultural land per 1 person

\begin{tabular}{|c|c|c|c|}
\hline Years & $\begin{array}{c}\text { World population, } \\
\text { billion people }\end{array}$ & $\begin{array}{c}\text { Agricultural land, } \\
\text { billion hectares }\end{array}$ & $\begin{array}{c}\text { The ratio of agricultural } \\
\text { land per 1 person, } \\
\text { ha/person. }\end{array}$ \\
\hline 1950 & 2,5 & 1,3 & 0,5 \\
\hline 1975 & 4 & 1,4 & 0,4 \\
\hline 2000 & 6 & 1,5 & 0,3 \\
\hline 2020 & 7,5 & 1,5 & 0,2 \\
\hline
\end{tabular}

The growth of the population has a negative impact on agricultural areas, reduces their productivity or even removes from circulation. As per capita arable land is shrinking, more and more countries are facing the threat of inability to provide food self-sufficiency.

This trend is evident in four major countries with the fastest population growth. Pakistan, Iran, Nigeria and Ethiopia, having reduced arable land per capita by $40-50 \%$ between 1960 and 1998, may receive a further 60-70\% reduction by 2050 (this is a cautious estimate that does not provide for further removal of agricultural land from circulation). As a result, four countries with a total population of more than 1 billion people may have 300 $600 \mathrm{~m} 2$ of arable land per person - less than a quarter of the area that accounted for one person in 1950 [5].

FAO studies show that there are significant reserves in the world for the production of both food and biomass in General. Each country has a certain potential for crop production, it is not used at full capacity. Many factors can impede this - such as non-use of technologies and new achievements of science and technology, not maintaining the fertility of land at the proper level. Figure 3 shows the grain yield potentials in some countries and how much they are used.

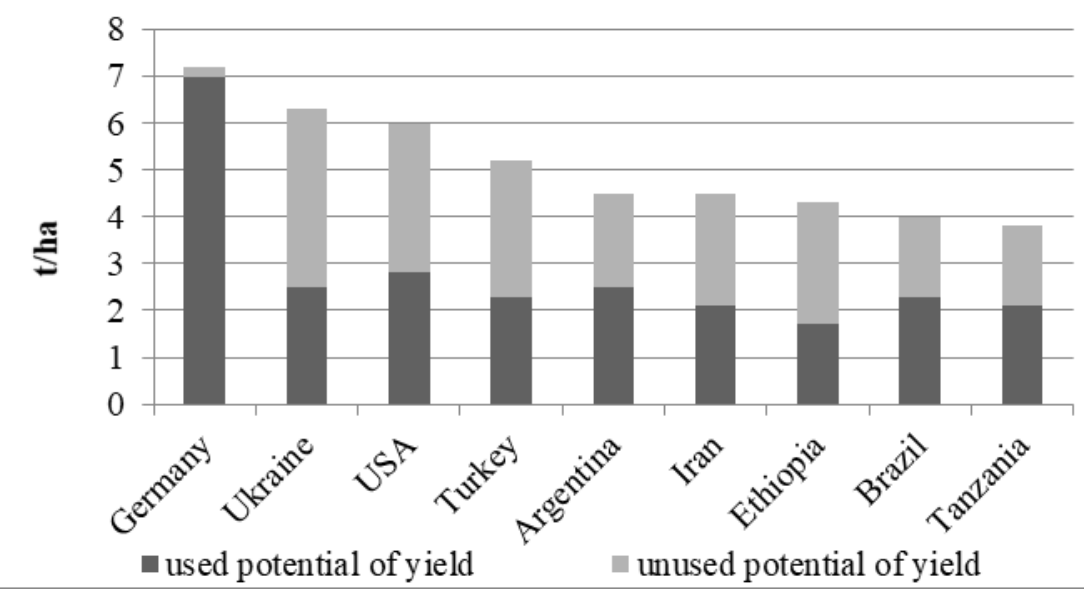

Fig. 3. Grain yield potential by country compared to actual yields. 
Source: according to FAO

As can be seen from figure 3, among these countries, Germany uses its potential most productively on the example of grain cultivation, with potentially possible $7.2 \mathrm{t} / \mathrm{ha}$ on average, agricultural producers receive 7 tons. Ukraine has a fairly low rate of potential use - only $2.5 \mathrm{t} / \mathrm{ha}$, with an average of possible $6.3 \mathrm{t}$. Therefore, countries such as Ukraine are the potential reserve of the world for obtaining additional biomass that can be used for food and energy needs.

Over the past few years, there have been some changes in global grain production. There have been significant fluctuations in both grain production and consumption. This led to significant changes in the amount of the accumulated reserve. A sufficient reserve in the world is considered to be at the level of $20 \%$, if this figure is lower, then as a response there are disturbances in the world markets, which leads to an increase in product prices. The world markets faced this situation at the end of 2006, when the world grain stock began to decline below the $20 \%$ mark. The ratio of cereal stocks to consumption will decline, especially in China, the EU and Russia, and global cereal stocks are expected to decline to 27.3 percent, marking the first decline in five years. It is expected that the world grain trade in 2018-2019 will amount to 414 million tons, which is 1.5 percent lower than last year's record," the FAO forecast says [6].

The main reason for the loss of the reserve share is the decrease in grain production in recent years with a parallel increase in their consumption. It should be noted that the growth of grain consumption is caused not only by the fact that a certain part of the products is used as biomass in alternative energy. The main reason for the increase in grain consumption can be considered an increase in food needs of the population, which is caused by both an increase in the world population as a whole, and an improvement in the material condition of a certain number of people, which led, as we indicated above, to an improvement in their food priorities - a significant amount of meat appeared in the consumer basket.

Production of meat products is quite energy-intensive activity. According to experts, the production of $1 \mathrm{~kg}$ of poultry meat requires about $3-4 \mathrm{~kg}$ of grain, pork $-7-8 \mathrm{~kg}$, and beef up to $14 \mathrm{~kg}$.

Table 2. Pork and beef production in the world, $\mathrm{mln} \mathrm{t}$

\begin{tabular}{|c|c|c|c|c|c|c|}
\hline \multirow{2}{*}{ Indicators } & \multicolumn{5}{|c|}{ Years } & $\begin{array}{c}2018 \text { as \% } \\
\text { of } 1990\end{array}$ \\
\cline { 2 - 7 } & 1990 & 1995 & 2000 & 2005 & 2018 & \\
\hline $\begin{array}{c}\text { Production: } \\
\text { Pork }\end{array}$ & 66 & 76 & 82 & 96 & 117 & 177 \\
\hline Beef & 51 & 48 & 50 & 52 & 69 & 135 \\
\hline
\end{tabular}

Of the total world grain harvest (estimated by the US Department of Agriculture, it is1.87 million tons), almost $37 \%$ went to feed livestock and poultry, which give not only meat but also milk and eggs. Today the stock of fodder grain is the main food reserve in case of food shortage.

According to the forecast of FAO, the total amount of meat consumption will rise from 211 million tons in 1997 to 513 million tons in 2050, that will greatly enhance the tension in the sphere of grain production.

Thus, it can be noted that there are several reasons that lead to instability in the food sector in the world.

A certain part of the rise in price of agricultural products is taken over by the production of energy from biomass. The fundamental difference between biomass and other fuels is the need for land for its cultivation. This raises the question of how and by whom this land will 
be used. There are two basic approaches to determining how land is used. The "technocratic" approach considers needs, then identifies biological sources, areas for cultivation and possible environmental effects. This approach ignores many of the local and most of the remote effects caused by the expansion of biomass plots and also ignores the opinion of local farmers who know the local conditions for the cultivation of certain crops. As a result, many biomass projects may fail. The "integrated" approach raises the question of how land should be used for sustainable development and considers what combination of methods and crops will lead to the optimal use of a particular piece of land to meet the needs for food, fuel, livestock feed, social development and the like. Such an approach requires a full understanding of the complex issues of land use.

It should be noted that biomass productivity can be increased, because in many countries it is low today and is less than 5 tons/ha per year for tree species under poor management. Improving efficiency is key to both creating competitive prices and making better use of suitable land. Improvement may include identification of fast-growing plants, successful reproduction and use of crop combinations, new knowledge of plant cultivation and biotechnology, which may increase plant productivity by 5-10 times compared to their natural capabilities [7-10].

A significant amount of grain, corn in the world is processed into bioethanol. A certain amount of space is allocated for rape to produce biodiesel. But only this sphere of production does not lead to those increases in food prices that we see at the present stage.

\section{Conclusion}

Much of the criticism of biomass use, especially in large-scale fuel production, is related to concerns that it distracts agriculture from food production, especially in developing countries. The main argument is that energy crop programmes compete with food crops in a variety of ways (agriculture, rural investment, infrastructure, water, fertilizers, educated human resources, etc.), which can lead to food shortages and higher prices. However, the so-called "food versus fuel" contradiction is exaggerated in many cases. The subject of discussion is more complex than is usually considered, as agricultural and food export policies are factors of great importance. The arguments should be analysed taking into account the actual situation in the world, individual country or region with the provision and need for food (increased food surpluses in most industrial and some developing countries), the use of food as feed for livestock, insufficient use of agricultural capacity, the potential for agricultural production, which increases, and the advantages or disadvantages of biofuel production. The main reason, we believe, is a rising world population and changing food priorities - more and more meat of all kinds is consumed, that is high-energy-consuming product.

\section{References}

1. H. Heletukha, T. Zheliezna, Bioenergy in Ukraine: the state, barriers and ways to overcome them, Bioenergy (2014)

2. O. Labenko, N. Perederiy, S. Kuzmenko. Market trends of oilseeds production in Ukraine, ISD, Nitra (2016)

3. N. Perederiy, S. Kuzmenko, Market of rapeseed: economic and bioenergetic perspective, Komprynt, 227 p. (2015)

4. N. Perederiy, World food security and bioenergy development, Innovational Economy(2008) 
5. L. Zaburanna, O. Faichuk, Food safety of Ukraine: qualitative dimension, NUBiP, 266 p. (2017)

6. O. Faichuk, "Green Economy" as a new paradigm of agricultural development, Scientific bulletin of NUBiP, 244 (2016)

7. T. Hutsol, S. Yermakov, Ju. Firman, V. Duganets, A. Bodnar Analysis of technical solutions of planting machines, which can be used in planting energy willow. Renewable Energy Sources: Engineering, Technology, Innovation. ICORES 2018 (20)

8. S. Yermakov, T. Hutsol, S. Slobodian, S. Komarnitskyi, M. Tysh Possibility of using automation tools for planting of the energy willow cuttings. Renewable Energy Sources: Engineering, Technology, Innovation. ICORES 2018 (2018)

9. K. Dziedzic, K. Mudryk, T. Hutsol, B Dziedzic Impact of grinding coconut shell and agglomeration pressure on quality parameters of briquette. Engineering for rural development. Jelgava, 23.-25.05.2018. pp.1884-1889 (2018) 